\title{
Comparison of Energy Harvesting Systems for Wireless Sensor Networks
}

\author{
James M. Gilbert* Farooq Balouchi \\ Department of Engineering, University of Hull, Hull HU6 7RX, UK
}

\begin{abstract}
Wireless sensor networks (WSNs) offer an attractive solution to many environmental, security, and process monitoring problems. However, one barrier to their fuller adoption is the need to supply electrical power over extended periods of time without the need for dedicated wiring. Energy harvesting provides a potential solution to this problem in many applications. This paper reviews the characteristics and energy requirements of typical sensor network nodes, assesses a range of potential ambient energy sources, and outlines the characteristics of a wide range of energy conversion devices. It then proposes a method to compare these diverse sources and conversion mechanisms in terms of their normalised power density.
\end{abstract}

Keywords: Energy harvesting, energy scavenging, wireless sensor networks (WSNs), energy management

\section{Introduction: Sensor networks and their applications}

Sensor networks are formed from a collection of sensing nodes which communicate with one another, typically through wireless channels, in order to collect spatially distributed data about their environment. Such networks have the potential to provide better quality data than single or small numbers of individual sensors in applications such as natural and built environmental monitoring, process monitoring, security and surveillance ${ }^{[1]}$. Wireless sensor networks (WSNs) may be considered as the third wave of a revolution in wireless technology. They promise to have a significant beneficial impact on many aspects of our human existence. These benefits include more efficient utilisation of resources, better understanding of the behaviour of humans, natural and engineering systems, and increased safety and security. Pervasive computing also has some possible negative environmental impacts, particularly in physical waste and energy consumption ${ }^{[2]}$.

In order to be cost effective in many applications, the sensor nodes must be low cost and low maintenance. This presents challenges in terms of sensor calibration, packaging for survival in harsh environments and, particularly, the efficient supply and utilisation of power. While the performance of battery technology is gradually improving and the power requirements of electronics is generally dropping, these are not keeping pace with the increasing demands of many WSN applications. For this reason, there has been considerable interest in the development of systems capable of extracting useful electrical energy from existing environmental sources. Such sources include ambient light, thermal gradients, vibration and other forms of motion. In this paper, we provide an overview of the energy sources available for energy harvesting or scavenging and a summary of the main methods considered for converting these energy sources into a form suitable for use in WSN nodes. The characteristics and power requirements of sensor networks

Manuscript received April 22, 2008; revised August 20, 2008

*Corresponding author. E-mail address: J.M.Gilbert@hull.ac.uk are outlined in Section 2, and the potential energy sources discussed in Section 3. Section 4 describes the methods of converting ambient energy into useful electrical power. Section 5 compares the relative merits of different approaches.

\section{$1.1 \quad$ Typical applications}

A large number of potential applications of sensor networks have been reported ranging from early research investigations to commercial systems ${ }^{[1]}$. A review of a broad range of applications is given in [3] as the basis for the proposal of a design space model.

\subsubsection{Environmental monitoring}

A widely considered area for the application of sensor networks is in environmental monitoring. Measurement of glacier dynamics using nodes capable of measuring location, temperature, pressure, and orientation at points inside the glacier over a period of several years was described in [4]. The research described in [5] used nodes on the sea bed to monitor pressure, temperature, conductivity, current, and turbidity. These nodes were connected to buoys on the surface to allow radio communication through self organising ad-hoc wireless networks. The Argo project ${ }^{[6]}$ uses a sensor network to observe the temperature, salinity, and current profile of the upper ocean. Nodes are attached to free-drifting carriers which cyclically sink to a depth of $2000 \mathrm{~m}$ and then resurface to allow communication with a satellite. WSNs have been considered for precision agricultural applications such as monitoring grape growing conditions $^{[7]}$. Here, nodes with temperature, soil moisture, light, and humidity sensors are deployed on a $20 \mathrm{~m}$ grid across a vineyard to provide information to guide the adaptation of water/fertilizer/pesticide supply to the needs of individual plants and to optimise harvesting.

\subsubsection{Animal tracking and control}

Tracking and controlling the movements of domestic and wild animals presents interesting challenges in WSNs. The breeding behaviour of birds was considered by Mainwaring et al. ${ }^{[8]}$ using sensor nodes installed inside burrows. Clusters of nodes, each capable of measuring humidity, pressure, temperature, and ambient light level, along 
with infrared sensors to detect the presence of the birds, form local networks and each cluster has a node fitted with a long-range directional antenna to pass cluster data to a base station. Nodes fitted to wild animals (e.g., wild horses, zebras, and lions) capable of roaming over a very large area was considered in [9]. Each node logs the animal's behaviour and environment and passes data to any other node which comes within range. At regular intervals, a mobile base station (e.g., a car or a plane) moves through the observation area and collects the recorded data from the animals it passes. In the case of [10], the WSN is used both to monitor behaviour and to control it. In this case, the positions of cattle are monitored and "virtual fences" created by using an acoustic stimulus to discourage an animal from crossing a defined line. The network of nodes are connected to a base station so that feeding behaviour can be monitored and virtual fences adjusted to improve usage of the feedstock.

\subsubsection{Safety, security, and military applications}

WSNs have been developed to assist rescue teams in saving people buried in avalanches ${ }^{[11]}$. By monitoring heart rate, respiration activity, orientation, and blood oxygen level, it is possible to automate the prioritization of victims and to guide rescuers to their location. Tracking of military vehicles using networks of nodes deployed by unmanned aerial vehicle (UAV) was considered in [12]. Data collected from the nodes by a UAV was used to identify the path and velocity of ground vehicles. Anti-tank landmines capable of self-monitoring for signs of tampering have been formed into networks so that, if an individual mine is disabled, a neighbouring device is able to take its place using rocket thrusters to effect the necessary movement ${ }^{[13]}$. Combining data from a network of acoustic sensors in order to determine the location of a sniper and the direction of the bullet based on the time of flight of muzzle blast was considered by Simon et al. ${ }^{[14]}$. Monitoring of buildings and emergency response personal has been considered by Yang and Frederick ${ }^{[15]}$ with the aim of improving safety in dealing with fires and other life threatening situations in the built environment.

\subsubsection{Built environment}

Monitoring of the internal environmental conditions and adaptation of heating, lighting, etc. in response to human occupancy and activity is a major potential application for sensor networks, whether based on wireless communications or on wired connections. In [16], a WSN was developed to monitor power consumption in large and dispersed office buildings with the aim of detecting locations or devices that are consuming a lot of electrical power.

\subsubsection{Health}

Health applications for WSNs include patient monitoring, drug administration, tracking of patients at home ${ }^{[17,18]}$ and doctors in hospitals. Body sensor networks ${ }^{[19]}$ are used in the medical sector; implanted medical devices with integrated wireless technology are used for therapeutic and diagnostic applications. Physicians can use this technology to monitor device performance and patient response without the need for invasive surgery. Drug manufactures are also interested in this technology to reduce their costs when introducing a new drug. The patients can be monitored wirelessly and data about the patient's internal chemistry can be analysed for abnormal reaction and side effects over a secure link. Yang ${ }^{[19]}$ undertook a thorough analysis of the wireless technologies available and concluded that the IEEE 802.15.4 wireless standard with provisions for body sensor networks (BSN) in the ZigBee application layer was the most appropriate for the body sensor networks. An analysis of the performance of medical sensor body area networking ${ }^{[20]}$ also endorsed the advantage of using IEEE 802.15.4 and ZigBee for medical sensor technologies.

\section{Power requirements in sensor net- work nodes}

The power consumed by a network node can be split between the various functions it has to perform. A number of authors have described the structure of a general sensor network node ${ }^{[21]}$. The key elements are illustrated in Fig. 1. It should be noted that not all of these elements will be present in all types of nodes. The power requirement of each element depends on the particular application and so it is difficult to generalise about which parts of the node consume the most power. For instance, it is commonly the case that actuators, if present, consume a large proportion of the total power. In addition, consumption depends on the operating mode of a device such as whether it utilises sleep mode to reduce consumption and how frequently it transmits and receives data. Correal and Patwari ${ }^{[22]}$ considered the split of power consumption in a typical node and concluded that communication functions consumed a large proportion of total power. The same paper outlined the design issues regarding the development of a highly energy efficient system architecture for embedded WSN; beginning with device technology and progressing to the application layer. The roadmap presented is claimed to be generic across the field of WSNs.

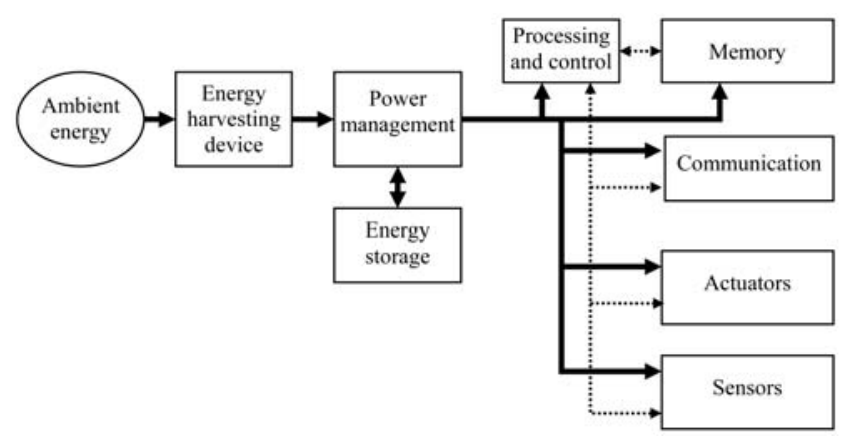

Fig. 1 A generic sensor network node with energy harvesting device

\subsection{Processing}

The choice of processor is a major factor in determining the size and power consumption of the node. The processing unit is responsible for managing data acquisition, handling communication protocols, scheduling and preparing data packets for transmission once it has gathered, filtered, and synchronised the data from the sensors. The consumption and performance of the processor depend on the architecture, technology, and clock speed utilised. A number of chip producers are offering low cost, low power processors 
for sensor networks with power consumption in the region of $12 \mathrm{pJ} /$ instruction $^{[21]}$.

\subsection{Communications}

There is a wide range of wireless communication standards available for networks with the choice of standards being determined by factors such as inter-node distance, data rate, power requirements, flexibility of network structure, the time required to establish communications and the cost of implementation. The most widely considered standards are grouped within the IEEE 802.11 standard for wireless local area networks (WLANs) and the IEEE 802.15 standard for wireless personal area networks (WPANs).

IEEE 802.11 is aimed at matching Ethernet speed, giving data rates of $2 \mathrm{Mbps}$ to around $200 \mathrm{Mbps}$ over a range of 10-100 m with seamless roaming between adjacent cells. In contrast, the IEEE 802.15 was focused on two main objectives; the space around a person or object that typically extends up to $10 \mathrm{~m}$ in all directions; and on creating a specification for low cost, low power, short range, and very small size radio transceivers. The working group responsible for creating the WPAN standard further differentiated the standard into three classes based on data rate, battery drain and quality of service (QoS). The high rate WPAN (IEEE 802.15.3) was classified suitable for multimedia application that require very high QoS. Medium rate WPAN (IEEE 802.15.1/Bluetooth) would handle cell phone to personal ditgital assistant (PDA) communication and have QoS suitable for voice communication. The low rate WPAN (IEEE 802.15.4/LR-WPAN) classified for industrial, residential, and medical applications with very low power consumption, low cost with relaxed data rate and QoS overheads ${ }^{[20,23]}$.

Specific communication protocols frequently considered for WSN applications include Bluetooth and its low end variant Wibree and ZigBee. There are a number of other systems developed for specific application areas such as $Z$-wave ${ }^{[24]}$, designed for home automation and control, and the proprietary communication standard developed by EnOcean ${ }^{[25]}$ for devices such as energy harvesting light switches.

In many sensor network applications, it is not necessary for nodes to be constantly active and communicating. It is often possible for nodes to enter a sleep mode for a significant proportion of time and wake up either at fixed time intervals or in response to some external event. Key con- siderations in this context are the time required for a node to wake up and re-establish communications and the ability to synchronise the waking of multiple nodes in a network. From low power sleep mode, a Zigbee node can join an existing network in about $3 \mathrm{~ms}$ whereas a Bluetooth node can take up to $3-10$ s to join a network ${ }^{[26]}$.

Examples of the power consumption of a selection of commercial sensor network nodes are given in Table 1 for a range of operating conditions. The average values given in Table 1 are based on an operating regime of communication (RX and TX, i.e., receive and transmit) for $1 \%$ of the time, processing for $10 \%$ of the time and sleeping for the remaining time.

\section{Energy sources suitable for scaveng- ing}

In order for a sensor network to operate, it requires electrical power and given that it is frequently desirable to install nodes in inaccessible locations, it can be difficult to provide a sufficiently large store of energy for long term operation or to replace the power source at appropriate intervals. Although the performance of non-renewable energy sources, such as batteries and fuel cells, has improved over the years ${ }^{[30]}$, this improvement is fairly gradual compared with other areas of electronics ${ }^{[31]}$ and cannot satisfy all of the simultaneous demands for long life, low volume, low weight and limited environmental impact.

There are a great many sources of energy and conversion devices which have been considered for energy harvesting ${ }^{[32,33]}$ and in order to compare different approaches, it is useful to consider the criteria for comparison. Clearly, a key consideration is whether the energy harvesting device can provide the level of power required by the sensor node but it is also important that the electrical power is at a suitable voltage and current level since conversion between voltage levels implies some dissipation of energy and, in general, the greater the ratio between input and output voltage, the greater the power losses.

In order to achieve a desired power level, some conversion devices can be appropriately scaled. Thus, for instance, if a photovoltaic (PV) cell is considered then an increase in power demand can be accommodated by an increase in cell area. However, other sources/converters cannot be so readily scaled. For instance, energy derived from human activity cannot generally be scaled up without either increasing the

Table 1 Summary of power consumption of commercial sensor network nodes

\begin{tabular}{|c|c|c|c|}
\hline & Crossbow $\mathrm{MICAz}^{[27]}$ & Intel IMote $2^{[28]}$ & Jennic JN5139 ${ }^{[29]}$ \\
\hline Radio standard & IEEE 802.15.4/ZigBee & IEEE 802.15 .4 & IEEE 802.15.4/ZigBee \\
\hline Typical range & $100 \mathrm{~m}$ (outdoor), $30 \mathrm{~m}$ (indoor) & $30 \mathrm{~m}$ & $1 \mathrm{~km}$ \\
\hline Data rate (kbps) & $250 \mathrm{kbps}$ & $250 \mathrm{kbps}$ & $250 \mathrm{kbps}$ \\
\hline Sleep mode (deep sleep) & $15 \mu \mathrm{A}$ & $390 \mu \mathrm{A}$ & $2.8 \mu \mathrm{A}(1.6 \mu \mathrm{A})$ \\
\hline Processor only & $8 \mathrm{~mA}$ active mode & $31-53 \mathrm{~mA}^{*}$ & $2.7+0.325 \mathrm{~mA} / \mathrm{MHz}$ \\
\hline $\mathrm{RX}$ & $19.7 \mathrm{~mA}$ & $44 \mathrm{~mA}$ & $34 \mathrm{~mA}$ \\
\hline $\mathrm{TX}$ & $17.4 \mathrm{~mA}(+0 \mathrm{dbm})$ & $44 \mathrm{~mA}$ & $34 \mathrm{~mA}(+3 \mathrm{dBm})$ \\
\hline Supply voltage (minimum) & $2.7 \mathrm{~V}$ & $3.2 \mathrm{~V}$ & $2.7 \mathrm{~V}$ \\
\hline Average & $2.8 \mathrm{~mW}$ & $12 \mathrm{~mW}$ & $3 \mathrm{~mW}$ \\
\hline
\end{tabular}

${ }^{*}$ Consumption depends on clock speed selected between $13-104 \mathrm{MHz}$ 
effect on the person concerned or increasing the number of people involved. While it may be possible to scale up a conversion device, many applications of sensor networks require nodes which are small and light weight. Thus, an important consideration is the power density (in either $\mathrm{W} / \mathrm{m}^{3}$ or $\mathrm{W} / \mathrm{kg}$ ) which can be achieved. In assessing power density, the volume and weight of associated energy storage may also be important.

A number of authors have proposed classification systems to categorise energy sources suitable for harvesting which, while broadly similar, do exhibit some differences. In [1], sources are grouped as human and environmental with kinetic and thermal considered as sub classes. Büren ${ }^{[34]}$ uses a similar classification of thermal energy, radiant energy, and mechanical energy sources when considering wearable micro-generators. This classification will be adopted here although mechanical source will be subdivided between those which are continuously present over long periods, such as air flow, those which involve vibration and those which involve short periods of energy availability such as footfall during walking.

\subsection{Electromagnetic radiation}

The electromagnetic spectrum contains regions where ambient energy levels are very high and other regions where the ambient levels are typically much lower. The efficiency of conversion into electrical energy also depends on the part of the spectrum considered. For convenience here, we will consider radiation in the region of the visible part of the spectrum and radio frequency radiation separately.

PV conversion of visible light to electrical power is well established and PV devices provide relatively high efficiency over a broad range of wavelengths. These devices are typically low cost and provide voltage and current levels that are close to those required for microelectronic circuits.

The average solar insulation at the top of the earth's atmosphere is approximately $1370 \mathrm{~W} \cdot \mathrm{m}^{-2}{ }^{[35]}$. The energy available for harvesting at a particular location on the earth's surface clearly varies with time of day, latitude and atmospheric conditions and the efficiency of conversion depends on the incidence angle to the PV device. Annually averaged surface received energy varies between around $300 \mathrm{~W} \cdot \mathrm{m}^{-2}$ near the equator to around $100 \mathrm{~W} \cdot \mathrm{m}^{-2}$ near the poles. For temperate regions, the daily average available shortwave energy varies from around $25 \mathrm{MJ} \cdot \mathrm{m}^{-2} \mathrm{day}^{-1}$ in summer to $1-5 \mathrm{MJ} \cdot \mathrm{m}^{-2} \cdot$ day $^{-1}$ in midwinter ${ }^{[36]}$. This does however depend on prevailing atmospheric conditions with heavy cloud cover resulting in a drop in available energy of approximately an order of magnitude. Given that commercially available PV cells provide a typical efficiency of around $15 \%$, the minimum average electrical power over a $24 \mathrm{~h}$ period in a temperate location is around $2 \mathrm{~W} \cdot \mathrm{m}^{-2}$. An important consideration in solar energy harvesting is that the energy is delivered for only part of the day and, assuming the sensor network is required to operate at the same level at all times, the energy gathered during the day must be stored for night time operation. Considering the same temperate location as considered above, a total electrical energy of $0.15 \mathrm{MJ} \cdot \mathrm{m}^{-2}$ is harvested over an $8 \mathrm{~h}$ period during the day in winter and must be stored to provide for the remaining $16 \mathrm{~h}$ of the day. Commercially available su- percapacitors have energy densities of around $5 \mathrm{~kW} \cdot \mathrm{h} \cdot \mathrm{m}^{-3}$. Thus, over a $24 \mathrm{~h}$ period, an average power of approximately $200 \mathrm{~W} \cdot \mathrm{m}^{-3}$ could be sored. For a $10 \times 10 \times 10 \mathrm{~mm}$ capacitor, this figure would correspond to an average power of $0.2 \mathrm{~mW}$, a figure that lies within the range of typical WSN nodes operating with extensive periods in sleep mode.

Ambient light levels in indoor environments are typically significantly lower than those found outdoors, with a typical light level being around $1 \mathrm{~W} \cdot \mathrm{m}^{-2}$ corresponding to about $0.15 \mathrm{~W} \cdot \mathrm{m}^{-2}$ of electrical energy ${ }^{[37]}$. The variation in light level with time is highly dependent on the nature of the indoor environment considered.

Although radio frequency signals can be used to power passive electronic devices such as radio frequency identification (RFID) tags, these must be carefully tuned to the frequency of the radio source and are typically only capable of transmitting power over a distance of a few meters ${ }^{[38]}$. Without the use of such a dedicated source of radio frequency (RF) energy, the ambient levels are very low and are spread over a wide spectrum. Harvesting useful levels of electrical energy in these ambient conditions would require large broadband antennas.

\subsection{Thermal}

Extraction of energy from a thermal source requires a thermal gradient. The efficiency of conversion from a thermal source is limited by the Carnot efficiency to

$$
\eta \leqslant \frac{T_{h}-T_{c}}{T_{h}}
$$

where $T_{h}$ is the absolute temperature on the "hot" side of the device, and $T_{c}$ is the absolute temperature on the "cold" side. Thus, the greater the temperature difference, the greater the efficiency of the energy conversion. A potential heat source in many environments would be a room heater. A domestic hot water radiator typically delivers approximately $1.4 \mathrm{~kW} \cdot \mathrm{m}^{-2}$ when heated to $50^{\circ} \mathrm{C}$ above ambient and so a relatively small section of such a radiator could provide a useable power source. Starner ${ }^{[35,39]}$ considered the use of body heat but noted that the relatively small difference between body temperature $\left(37^{\circ} \mathrm{C}\right.$ and ambient $\left(20^{\circ} \mathrm{C}\right.$ means that the Carnot efficiency is limited to $5.5 \%$ and so the entire body area would only yield $6.4 \mathrm{~W}$ from the total of approximately $116 \mathrm{~W}$ dissipated by a typical human while sitting. Using only part of the body would cause the resulting power to decrease and, because blood flow would be reduced in the area covered, the available energy would decrease further. Starner ${ }^{[39]}$ concluded that a device covering just the neck could potentially deliver 0.2 $0.32 \mathrm{~W}$. The available energy is also affected by the thermal resistance of the source and sink of the thermal energy.

\subsection{Mechanical energy sources}

Sources of mechanical energy may usefully be grouped as those dependent on motion which is essentially constant over extended periods of time, such as air flow used in a turbine, those dependent on intermittent motion, such as human footfall and those where the motion is cyclic, as in vibration sources. These different types of sources will be considered separately. 


\subsubsection{Steady state mechanical sources}

Sources of ambient energy which are essentially steady state are based around fluid flow, as in wind and air currents and water flow either in natural channels or through pipes, or around continuous motion of an object such as a rotating shaft. Fluid flow based sources of energy are widespread and used on the macro scale for electrical power generation as in wind turbines and hydroelectric plants but have also been considered for smaller scale harvesting applications. Starner ${ }^{[39]}$ considered the potential for energy harvesting from blood flow and breathing in human subjects and determined that significant power was available but that these might not be acceptable to subjects.

\subsubsection{Intermittent mechanical sources}

Energy is available from motion which may be cyclic in nature but in which the energy is only available for a short part of the cycle. Examples of this type include energy available from vehicles passing over an energy harvesting device $^{[40]}$ and intermittent human activity such as walking or typing where, for instance, footfall occurs over a period of milliseconds during a gait cycle of around one second. Harvesting of energy from these intermittent sources was also considered by Starner ${ }^{[39]}$ who concluded that available energy ranged from around $7 \mathrm{~mW}$ from finger motion during typing to $67 \mathrm{~W}$ for lower limb movement. This paper also considered the effect that extracting this energy would have on the subject and concluded that inconvenience to the subject could only be avoided if significantly lower power levels were extracted. A particularly attractive source of energy in this context is footfall or heel strike since normal walking involves dissipation of significant energy in the shoe and walking surface, so the user might be unaware if some of this energy were converted to electrical energy. It may readily be calculated that a subject weighing $60 \mathrm{~kg}$ must apply a force of at least $588 \mathrm{~N}$ through the foot during walking (the peak force is typically $25 \%$ above body weight during walking and up to $2.75-3$ times body weight during running $\left.{ }^{[41]}\right)$. If this is accompanied by a $10 \mathrm{~mm}$ deflection of the floor or shoe, then the available energy is $5.88 \mathrm{~J}$ and assuming two steps per second, an available power of $5.88 \mathrm{~W}$ per foot. Similar calculations may be carried out for the case of vehicles passing over a deflection device and, given the far greater weight, a significantly greater energy level is found (for example, a single $40 \mathrm{t}$ vehicle causing a $10 \mathrm{~mm}$ deflection could provide $4 \mathrm{~kJ}$ ), although clearly the frequency of vehicle passage will affect the average power level achievable.

\subsubsection{Vibration}

Vibration energy is available in most built environments. The energy that can be extracted from a vibration source depends on the amplitude of the vibration and its frequency. It also depends on the extent to which the presence of an energy harvesting device affects the vibration. This, in turn, depends on the mass of the harvesting device relative to that of the vibrating mass. Vibration sources vary considerably in amplitude and dominant frequency. Roundy et al. ${ }^{[42]}$ presents measurement for a number of vibration sources that indicate that the amplitude and frequency varies from $12 \mathrm{~m} \cdot \mathrm{s}^{-2}$ at $200 \mathrm{~Hz}$ for a car engine compartment to $0.2 \mathrm{~m} \cdot \mathrm{s}^{-2}$ at $100 \mathrm{~Hz}$ for the floor in an office building with the majority of sources measured having a fundamental frequency in the range $60-200 \mathrm{~Hz}$. Vibration present in most environments is not made up of a single frequency but is typically made up of a number of fundamental frequencies and their harmonics. For instance, the vibration data shown in Fig. 2, which is taken from a domestic freeze, indicates a fundamental frequency of $50 \mathrm{~Hz}$ with an acceleration amplitude of $0.1 \mathrm{~m} \cdot \mathrm{s}^{-2}$ with the 2nd and higher harmonics present at lower amplitudes. As will be seen in Section 4.1, the energy that can be extracted from a vibration source depends on the frequency and amplitude and, since the majority of vibration based conversion devices have a relatively narrow range of operating frequencies, it is important that the nature of the source be understood. It is difficult to establish a strong relationship between the amplitude and fundamental frequency of ambient sources because of the limited frequency range typically found. However, if a harvesting device is tuned to a frequency above about $200 \mathrm{~Hz}$, it may be necessary to use harmonics rather than the fundamental frequency of the source. The amplitude of these harmonics tends to be of significantly lower amplitude than the fundamental.

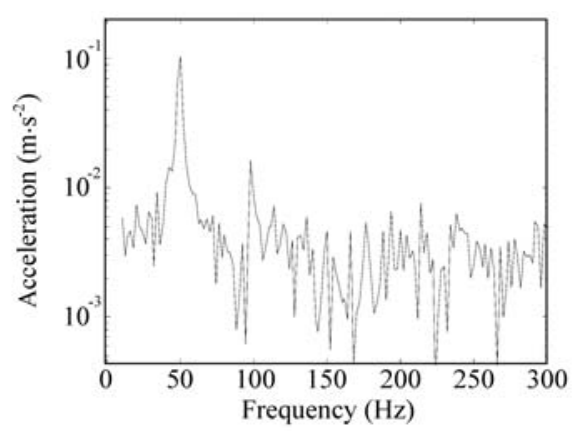

(a)

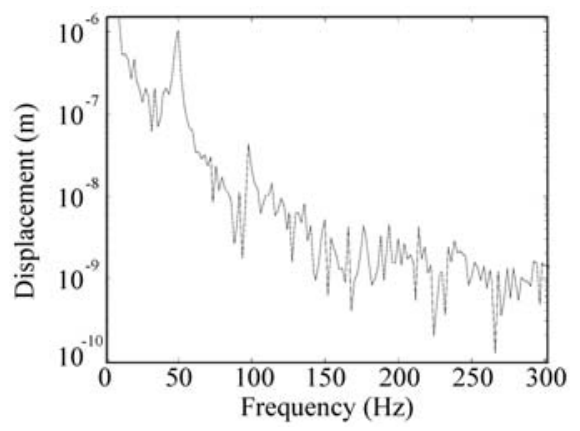

(b)

Fig. 2 Vibration amplitude as a function of frequency for a domestic freeze. (a) Acceleration magnitude; (b) Displacement amplitude

It is also important to note that the frequency of the dominant vibration modes depends, in many situations, on the operating parameters of the equipment causing the vibration. Thus, for instance, the dominant vibration frequency on a domestic fan changes when the air flow is partially obstructed. Similarly, testes on an energy scavenging node used to extract energy from a pump aboard a marine vessel found that the energy generation fell substantially due to changes in pump speed ${ }^{[43]}$. 


\section{Energy conversion devices}

The effectiveness of an energy harvesting system depends on both the available energy and on the efficiency with which that energy can be converted to useable electrical energy. A broad range of conversion devices is available, each with its own advantages and disadvantages, as will be discussed in the following sections.

\subsection{Electromagnetic radiation}

As noted in Section 3.1, electromagnetic radiation sources may be grouped according to the part of the electromagnetic spectrum in which they reside. Radiation around the visible light part of the spectrum contains abundant energy in many environments and this energy may be conveniently converted to electrical energy. A detailed discussion of photovoltaic conversion is beyond the scope of this paper (see [44] for an extensive survey of the topic) but it may be noted that conversion efficiencies of around 15-20\% are readily achievable in commercial devices. Conversion of ambient RF signals to useful electrical energy is far more challenging due to the broadband, low intensity nature of the signals typically present. Systems have been reported which are capable of harvesting sufficient energy for simple electronic circuits but these must generally be positioned close to the source of RF power. The limitations of such systems are outlined in [45].

\subsection{Thermal}

Conversion of energy derived from thermal gradients is the basis for many large scale power generation (e.g., steam turbines) but such technologies are not generally scalable to the level required for sensor network nodes. At this smaller scale, solid state devices are more attractive. Although the voltage and power levels associated with an individual thermocouple is very low, arrays of multiple thermocouples may be used in order to increase the voltage and power level. Stordeur and Stark ${ }^{[46]}$ combined 2250 thermocouples in a generator capable of producing $20 \mu \mathrm{W}$ for a temperature difference of $20 \mathrm{~K}$. A commercial device based on similar technology provides $100 \mu \mathrm{W}$ from a $10 \mathrm{~K}$ temperature difference in a $9.3 \mathrm{~mm}$ diameter device $1.4 \mathrm{~mm}_{\text {thick }}{ }^{[47]}$.

\subsection{Steady state mechanical}

Conversion of steady state sources of mechanical energy, such as air or water flow, has been investigated by several researchers. Yumita and Kumagai ${ }^{[48]}$ describes a device suitable for fitting to a domestic water tap capable of extracting energy from the water flow using a turbine. A miniature turbine designed for use in air flow is described in [49]. This device used a $13 \mathrm{~mm}$ diameter, $1 \mathrm{~mm}$ thick turbine disk and was capable of producing $1 \mathrm{~mW}$ of electrical power. A larger device designed for use in heating, ventilating, and air-conditioning (HVAC) ducts is described in [50]. A turbine with a diameter of approximately $10 \mathrm{~cm}$ was shown to produce around $27 \mathrm{~mW}$ for an air flow rate of 1000 feet per minute, which is within the range found in an HVAC duct but greater than that found in most other environments.

\subsection{Vibration}

Vibration based energy harvesting has received considerable research interest ${ }^{[42,51-53]}$. In this section, the underlying principles of vibration based conversion will be considered, and it will be shown how different conversion methods affect this behaviour. The development of more sophisticated types of converters, which aim to overcome some of the limitations of simpler devices, will then be discussed.

Vibration based energy harvesting devices are generally modelled as mass, spring, and damper systems of the type illustrated in Fig. 3.

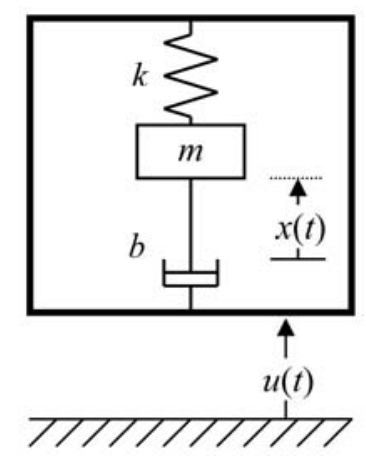

Fig. 3 Model of a translational inertial generator

The system is composed of a seismic mass, $m$, and a spring of stiffness $k$. The seismic mass is suspended within the outer case and the entire device moves relative to the inertial frame with the position of the case at time $t$ described by $u(t)$. The position of the seismic mass relative to its equilibrium position in the case is $x(t)$. Losses within the system and energy extracted are represented by the damper. The characteristics of this damping element depend on the type of energy conversion utilized but if it is assumed that the damping force is proportional to velocity $\dot{x}(t)$ with viscous damping coefficient $b$, then the equations of motion may be written as

$$
m \ddot{x}(t)+b \dot{x}(t)+k x(t)=-m \ddot{u}(t) .
$$

Assuming that the vibration of the device relative to the inertial frame is described by $u(t)=U \sin (\omega t)$, then the steady state solution for $x(t)$ is

$$
x(t)=\frac{\omega^{2}}{\sqrt{\left(\frac{k}{m}-\omega^{2}\right)^{2}+\left(\frac{b \omega}{m}\right)^{2}}} U \sin (\omega t+\phi) .
$$

It can be shown ${ }^{[42]}$ that the total power dissipated in the damping element is

$$
P_{d}=\frac{m \xi_{T} Y^{2}\left(\frac{\omega}{\omega_{n}}\right)^{3} \omega^{3}}{\left[1-\left(\frac{\omega}{\omega_{n}}\right)^{2}\right]^{2}+\left[2 \xi_{T}\left(\frac{\omega}{\omega_{n}}\right)\right]^{2}}
$$

where $\omega_{n}=\sqrt{k / m}$ is the natural frequency of the resonant system and $\xi_{T}=b /\left(2 m \omega_{n}\right)$ is the damping factor. For a given amplitude of acceleration, $A$, the amplitude of the 
displacement decreases as $Y=A / \omega^{2}$, and so (2) becomes

$$
P_{d}=\frac{m \xi_{T} A^{2} \omega^{2} \frac{\omega^{2}}{\omega_{n}^{3}}}{\left[1-\left(\frac{\omega}{\omega_{n}}\right)^{2}\right]^{2}+\left[2 \xi_{T}\left(\frac{\omega}{\omega_{n}}\right)\right]^{2}} .
$$

The relationship given in (3) is plotted in Fig. 4 using normalized logarithmic axes for a range of values of $\xi_{T}$. It can be seen that the peak power occurs when the vibration frequency matches the resonant frequency $\left(\omega=\omega_{n}\right)$. It may also be noted that increasing the damping, $\xi_{T}$ has the effect of reducing the peak power but increasing the bandwidth. Thus, if the vibration has a fixed frequency then a low level of damping is preferable but if the source frequency varies, it may give better average power to use a higher damping factor.

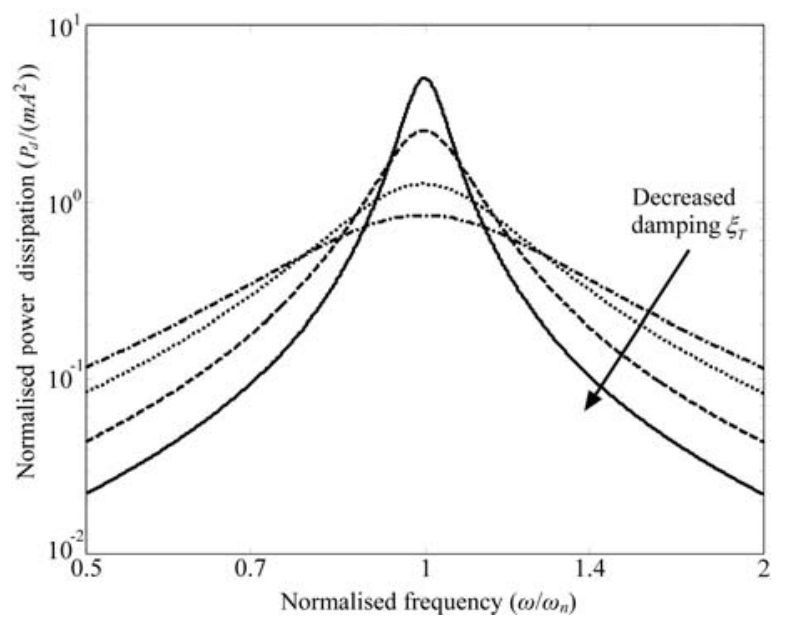

Fig. 4 Relationship between total dissipated power and frequency for vibration resonator

The peak power may be derived from (3) with $\omega=\omega_{n}$ as

$$
P_{d}=\frac{m A^{2}}{4 \omega_{n} \xi_{T}} .
$$

If the total damping is split between the element representing energy converted to electrical energy, $\xi_{e}$, and the parasitic element, $\xi_{p}$, representing losses, then the useful power can be written as ${ }^{[42]}$

$$
P_{e}=\frac{m A^{2} \xi_{e}}{4 \omega_{n}\left(\xi_{e}+\xi_{p}\right)^{2}} .
$$

This is maximised when $\xi_{e}=\xi_{p}$ giving

$$
P_{e}=\frac{m A^{2}}{16 \omega_{n} \xi_{e}} .
$$

This indicates that the power generated will tend to infinity as $\xi_{e}$ tends to zero. However, this increase is limited by a number of factors. It is not generally possible to reduce the parasitic losses represented by $\xi_{p}$ to an arbitrarily small value. The amplitude of $z$ when operating at $\omega=\omega_{n}$ is $Z=Y / 2 \xi_{T}$ and so decreasing $\xi_{e}$ implies increasing the range of movement which the resonator is capable of making without damage. This also implies an increase in the forces applied by the vibration source to the resonator and, if these forces become sufficiently large, they will affect the behaviour of the vibration source.

If it is assumed that the movement of the seismic mass is limited to an amplitude of $Z<Z_{\max }$ then $\xi_{T}>Y /\left(2 Z_{\max }\right)$ and so $\xi_{e}>Y /\left(4 Z_{\max }\right)$, which may be rewritten as $\xi_{e}>$ $A /\left(4 \omega_{n}^{2} Z_{\max }\right)$ and hence

$$
P_{e}<\frac{m A Z_{\max } \omega_{n}}{4}
$$

The mass of the seismic mass is limited by the linear dimensions and the material density and assuming a cubic mass with sides of length $d$ and density $\rho$, then (5) will be rewritten as

$$
P_{e}<\frac{d^{3} \rho A Z_{\max } \omega_{n}}{4} .
$$

The maximum vibration amplitude is likely to be proportional to the linear dimensions of the seismic mass and so setting $Z_{\max }=d$, the maximum electrical power can be written as

$$
P_{\text {max }}=d^{4} \rho A \omega_{n} .
$$

Thus, for a given vibration source, the harvested energy is proportional to the 4 th power of the linear dimensions. Alternatively, given that the mass is $m=d^{3} \rho$, the maximum power is limited by

$$
P_{e \max }=m^{\frac{4}{3}} \rho^{-\frac{1}{3}} A \omega_{n} .
$$

The relationships given above predict the maximum power which could be achieved if there were no losses in the mechanical to electrical transduction process. The efficiency of this transduction is one of the key considerations in the different types of conversion discussed below.

\subsubsection{Piezoelectric conversion}

Piezo electric materials exhibit the property that if they are mechanically strained, they generate an electric field proportional to the strain. Conversely, when an electric field is applied the material undergoes strain. These anisotropic relationships are described by the piezoelectric strain constant, $d$, which gives the relationship between applied stresses while the electro-mechanical coupling coefficient, $k$, describes the efficiency with which energy is converted between mechanical and electrical forms. This latter coefficient is important in determining the efficiency of a resonant generator since the overall efficiency of a piezo element clamped to a substrate and cyclically compressed at its resonant frequency is ${ }^{[51]}$

$$
\eta=\frac{\frac{k^{2}}{2\left(1-k^{2}\right)}}{\frac{1}{Q}+\frac{k^{2}}{2\left(1-k^{2}\right)}}
$$

where $Q$ is the quality factor of the resonator. As $Q$ becomes larger, the efficiency tends towards unity but for typically achievable $Q$ factors, the efficiency increases significantly for higher values of $k$.

Although there is a wide range of materials that exhibit piezoelectric behaviour, the most commonly used materials in energy harvesting applications are lead zirconate titanate (PZT), barium titanate $\left(\mathrm{BaTiO}_{3}\right)$ and polyvinylideneflouride (PVDF). PZT is a brittle piezoceramic which has a high electro-mechanical coupling coefficient, $k$, of up to 0.75 . PVDF is a polymeric material available as flexible sheets and is more robust than PZT but has a much lower 
$k$ value of around $0.12-0.15$. Because of its greater stiffness and higher $k$ value, PZT has generally been preferred for vibration based energy harvesting devices while impact and other intermittent type harvesting devices have made use of either PVDF or PZT, depending on the particular design.

The design of a piezoceramic vibration based energy harvesting device has to overcome a number of conflicting aims. Because piezoceramics possess high stiffness, structures in which they are formed tend to have high resonant frequencies while, as seen in Section 3.3.3, ambient vibrations tend to have greatest amplitude at relatively low frequencies. Also, as seen in Section 3.3.3, there is a trade-off between peak output power for a resonant device and the bandwidth to which the device responds. In addition, efficient operation of the piezo material requires that all of the material undergoes a similar strain. This strain should ideally be large but should not be sufficient for the material to be damaged. The development of piezoceramic resonators has been a process of identifying materials, configurations, and dimensions which attempt to balance these competing aims.

Due to the high stiffness of piezoceramics, they are not generally used in compressive mode ${ }^{[42]}$ since this results in a resonant frequency significantly above the frequency of vibrations found in most situations. A number of nonresonant compressive mode devices are reviewed in [54]. A more attractive configuration is to form the piezoceramic into a cantilever arrangement as shown in Fig. 5 where layers of piezoceramics are bonded to a substrate, typically made from a suitable metal. This structure allows a lower resonant frequency to be achieved while producing large strains in the piezoceramic. Where two layers of piezo material are used, the structure is referred to as a bimorph. In this case, the piezo layers may either be connected in series or parallel. If only a single piezo layer is used, the structure is referred to as a unimorph.

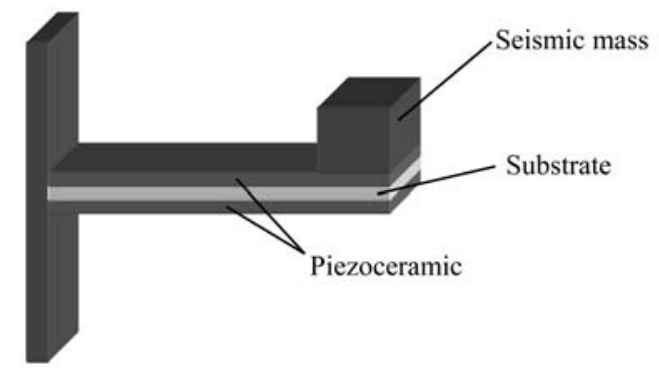

Fig. 5 Piezoceramic cantilever resonator

The uniform cantilever arrangement shown in Fig. 5 results in a non-uniform distribution of strain in the piezo material while a suitably tapered cantilever formation can ensure uniform strain. This was investigated in an early work by Glynne-Jones et al. ${ }^{[5]}$ and subsequent modelling and practical studies by Roundy and co-workers ${ }^{[56,57]}$ showed significantly higher power for a given volume of piezo material using a tapered cantilever. Straight cantilevers, while not giving uniform material strain, are more readily modelled ${ }^{[58]}$ than the tapered form. Roundy et al. ${ }^{[42]}$ and Sodano et al. ${ }^{[59,60]}$ investigated a number of material combinations and manufacturing techniques for straight cantilevers. Comparisons between unimorph and bimorph structures ${ }^{[61]}$ have shown that different structures are suited to differing levels of excitation. A number of variations on this type of structure have been investigated. Several authors ${ }^{[54,62,63]}$ have investigated the use of initially curved, or "pre-stressed" beams which have been demonstrated to give significantly higher output power than nonprestressed versions. A further development of this concept by Baker et al. ${ }^{[57]}$ involved the use of a curved beam between two pinned joints which could snap between concave and convex curves in response to excitation. This resulted in improved efficiency compared to uncompressed beams.

As noted in Section 3.3.3, ambient sources do not necessarily produce a fixed frequency of vibration but give a range of frequencies depending on operating conditions. Given that vibration based converters operate most efficiently with a narrow bandwidth, they are not naturally suited to variable frequency sources. There has therefore been considerable interest in converters that can operate over a range of frequencies. There are essentially three approaches to achieving this. The first approach is to tune the resonant frequency of the converter to match the vibration present. This self-tuning may be achieved by adding a passive auxiliary structure ${ }^{[64]}$ or by active tuning where, for instance, the effective mass or stiffness are altered ${ }^{[65,66]}$. Although these have shown some improvement in efficiency, it is not clear whether the extra power generated is greater than that used by the self tuning system. The second approach is to make the converter respond to a broader range of frequencies by combining several mass and/or spring elements. Shahruz ${ }^{[67,68]}$ considered using a series of mechanically independent cantilevers tuned to different frequencies with the electrical outputs combined. This gives a broadband converter but the size of the device and the complexity of the electronics increases significantly. A more space efficient approach has been adopted by Roundy et al. ${ }^{[56,67]}$ in which a single beam has been used but with three masses attached in such a way that the structure is able to vibrate at several frequencies. This gives a broader frequency band but it is not clear how this will affect the peak power output. The third approach may be termed frequency conversion. In the device proposed by Rastegar et al. ${ }^{[69]}$, a low frequency oscillator is tuned to ambient vibrations but this is coupled into a high frequency resonant structure which performs the conversion to electrical energy. Experimental results for this proposed method are not presented but it is apparent that ensuring efficient coupling between low and high frequency oscillators is critical to the efficiency of the overall structure. A fuller discussion of recent developments in piezo based devices is presented in [54].

\subsubsection{Electrostatic conversion}

Electrostatic conversion is based on the formation of a parallel plate capacitor onto which a charge is introduced from an external power source. Once the external source is disconnected then varying the capacitor configuration (plate overlap area or plate separation) causes the voltage and/or charge on the capacitor to vary. The varying voltage or charge may be extracted to provide electrical energy to a load.

For a parallel plate capacitor with plate area $A$ and plate separation $d$, the capacitance is approximately

$$
C=\varepsilon \frac{A}{d}=\frac{Q}{V}
$$


where $\varepsilon$ is the dielectric constant of the insulating material between the plates, $Q$ and $V$ are the charge and the voltage on the capacitor, respectively. The energy stored on the capacitor is

$$
E=\frac{1}{2} Q V
$$

If the charge is held constant, then combining (9) and (10), the energy becomes

$$
E=\frac{Q^{2} d}{2 \varepsilon A}
$$

while if the voltage is constrained, the energy becomes

$$
E=\frac{\varepsilon A V^{2}}{2 d}
$$

Attempts to change the stored energy by moving the capacitor plates causes a reaction force. This reaction force depends on whether the gap or the overlap area of the capacitor is varied and on whether the voltage or the charge are constrained. For instance, if the separation of a parallel plate capacitor is changed and the charge constrained, then since force is the rate of change in energy with distance, the force can be found from (11) as

$$
F=\frac{Q^{2}}{2 \varepsilon A}
$$

while if the voltage is constrained, the force becomes

$$
F=\frac{\varepsilon A V^{2}}{2 d^{2}}
$$

Thus in the first case, the reaction force is constant while in the second it is proportional to $1 / d^{2}$. These differences will affect the response of the resonant spring mass system, particularly if the forces are larger than other sources of damping.

Roundy ${ }^{[37]}$ considered three possible structures named out-of-plane gap closing in which the separation of a simple parallel plate capacitor varies (as described above); in-plane gap closing, in which the separation of interdigitated fingers varies and in-plane overlap varying in which the overlap area of interdigitated fingers varies in response to vibration. Each combination of structure and voltage or charge constraint results in a different reaction force relationship ${ }^{[42]}$. Roundy ${ }^{[37]}$ went on to consider the relative magnitude of fluid damping and electrostatic forces for each structure considered and concluded that in-plane gap closing structures offer the greatest power output capability. This and the other structures mentioned have been studied by a number of authors. In-plane overlap varying was considered by Menigner et al. ${ }^{[70]}$ and Ma et al. ${ }^{[71]}$; in-plane gap closing by Despresse et al. ${ }^{[72]}$ and out-of-plane gap closing by Tashiro et al. ${ }^{[73]}$. A common issue in all of these electrostatic converters is that the capacitor requires charging from an external source before harvesting can begin.

\subsubsection{Electromagnetic Conversion}

Electromagnetic transduction is based on the generation of voltage resulting from relative movement between a magnet and a coil. The voltage generated in a square coil made up of $N$ turns of side length $l$ moving through a magnetic field with flux density $B$ at a velocity $\dot{x}(t)$ is $v(t)=N l B \dot{x}(t)$. Assuming that $\dot{x}(t)$ varies sinusoidally with frequency $\omega$ and that the coil has resistance $R_{c}$ and inductance $L_{c}$ and is connected to a resistive load $R_{L}$, then the load current is $i=v /\left(R_{L}+R_{c}+j \omega L_{c}\right)$ and since the resulting force is $F=B l N$, the effective damping in (1) becomes

$$
b=\frac{(N l B)^{2}}{R_{L}+R_{c}+j \omega L_{c}} .
$$

Because of the reactive behaviour of the inductance, there is a phase shift in the damping but it is generally assumed that the inductance is insignificant at the vibration frequency ${ }^{[70]}$. It can then be shown that the maximum electrical power delivered to a matched load when tuned to the frequency of the vibration source is ${ }^{[70,74,75]}$

$$
P_{e}=\frac{m A^{2}}{16 \omega_{n} \xi_{m}}\left(1-\frac{R_{c}}{R_{L}}\right)
$$

This may be seen to be similar to the expression derived for the piezo device operating in similar conditions except that this takes explicit account of the effect of the internal resistance of the coil.

A number of authors have considered electromagnetic vibration energy harvesters ranging from micro electro mechanical (MEM) devices ${ }^{[75-78]}$ to larger scale devices with dimensions of the order of a few centimetres ${ }^{[42,79]}$. A range of material combinations and magnet/coil configurations have been considered in research devices and a limited number of commercial units developed ${ }^{[80]}$. It has also been shown that an optimised device is capable of converting up to $30 \%$ of the total energy supplied into useful electrical energy ${ }^{[81]}$.

\subsection{Intermittent mechanical conversion}

As noted when discussing energy sources in Section 3, there are a number of sources of mechanical energy which are repetitive but are non-sinusoidal. For instance, footfall occurs at an approximately fixed frequency but is characterised as a series of impacts rather than a continuous sinusoidal variation. Conversion systems suitable for this type of energy source are significantly different from those used for vibrational sources. Given that these sources typically deliver power over a small part of the overall period, the challenge here is to devise mechanically robust devices able to convert the energy in an efficient manner without being large or heavy. The majority of studies reported in the literature have been aimed at capturing energy from footfall, since this is one of the most promising sources in human energy harvesting, although other researchers have investigated energy harvesting from moving traffic ${ }^{[40]}$.

\subsubsection{Piezoelectric conversion}

Starner and Paradiso ${ }^{[45]}$ considered a number of shoe insert energy harvesting devices. They predicted that an insert constructed from 40 plies of PVDF positioned to extract energy from the flexing of a shoe sole should be capable of generating $5 \mathrm{~W}$ when deflected by $5 \mathrm{~cm}$ by a $52 \mathrm{~kg}$ user. The device constructed was smaller than that used as the basis for these predictions and possessed fewer PVDF layer. The measured peak power from this device was $15 \mathrm{~mW}$ with an average over the entire gait of $1.3 \mathrm{~mW}$. A second device, based on a PZT unimorph, was developed to capture energy from heel strike. This was found to deliver a peak power of $60 \mathrm{~mW}$ and an average of $1.8 \mathrm{~mW}$. 
A further development of this device used two unimorphs arranged back-to-back and achieved an average power of $8.4 \mathrm{~mW}$. It was noted that this represented an efficiency of mechanical to electrical energy of only around $1 \%$.

The efficiency of piezoelectric conversion is improved if the device is operated at its resonant frequency and so consideration has been given to methods to convert the low frequency footfall energy pulses to higher frequencies matched to piezo resonance. Antaki et al. ${ }^{[82]}$ used a passive hydraulic pulse amplifier to effect this frequency conversion and obtained average power of up to $700 \mathrm{~mW}$ during walking while Hagood et al. ${ }^{[83]}$ used an active valve to chop the hydraulic flow at the resonant frequency of a PZT resonator.

\subsubsection{Electro-active polymers (EAP) conversion}

A number of polymeric materials exhibit significant strain when subjected to electric field and similarly are capable of generating electrical power when strained. Appropriate polymers are capable of undergoing significant strain, give efficient conversion between mechanical and electrical energy and have low density. A heel strike device based on electro-active polymers (EAPs) has been demonstrated which is capable of developing $0.8 \mathrm{~J} \cdot \mathrm{step}^{-1}$, indicating a power of around $2 \mathrm{~W}$ at normal walking speed if fitted to both feet ${ }^{[84,85]}$. The voltages generated by EAPs are generally high and so efficient conversion of these high voltages to more usable levels remains problematic. The durability of the materials has also been a matter for concern ${ }^{[84]}$.

\subsubsection{Electromagnetic conversion}

Given the design and material constraints imposed on electrical machines, they typically posses a limited range of speeds at which they operate efficiently. The majority of machines are most efficient when operated at high speeds and low force/torque. Thus, there is an inherent mismatch with most intermittent sources of mechanical energy which have relatively high force but low average speed. One method for improving this matching is through the use of gears ${ }^{[86]}$ but this introduces significant inefficiency and increasing the gear ratio used typically increases the losses.

One approach to ameliorate the problems associated with the high impact forces found in footfall and similar intermittent energy sources is to attempt to store the energy so that the conversion between mechanical and electrical energy can be performed over a longer period, thus making use of physically smaller devices. Mechanical energy may be stored in springs, moving masses or in fluid flow or a fluid pressure vessel. Kymissis et al. ${ }^{[87]}$ demonstrated a system composed of gears, a spring and flywheel used to drive a generator which was able to produce an average of $250 \mathrm{~mW}$ from a $3 \mathrm{~cm}$ deflection of the heel during normal walking. It was noted that this device was obtrusive for the user.

A mechanism developed by the author, based on mechanical analogues of electrical switched mode power supplies ${ }^{[87]}$, has been used as an energy harvesting shoe heel insert. In this device, energy supplied during compression is stored in a spring, and when the heel lifts off the stored, energy is transferred through a set of gears and a freewheel device to a flywheel and generator. Since the impact energy is only transferred to the spring, it is not necessary to use such large and robust gears as those which would be required for direct conversion during the heel strike impact. The device, shown in Fig. 6, has dimensions $50 \times 65 \times 30 \mathrm{~mm}$ and allows a deflection of $14 \mathrm{~mm}$. When driving a matched load of $70 \Omega$ it is capable of producing an output energy of $90 \mathrm{~mJ}$ from a mechanical input energy of $450 \mathrm{~mJ}$ at a peak voltage of approximately $7 \mathrm{~V}$. Thus for a speed of $1.1 \mathrm{steps} \cdot \mathrm{s}^{-1}$, this represents an average power of $100 \mathrm{~mW}$.

The lower voltages typically derived from electromagnetic generators are more compatible with most electronic circuits than the high voltages of around $150 \mathrm{~V}$ typically derived from piezo converters ${ }^{[88]}$. While these high voltages can be reduced to more appropriate voltages for electronic circuits, this conversion process introduces further losses.

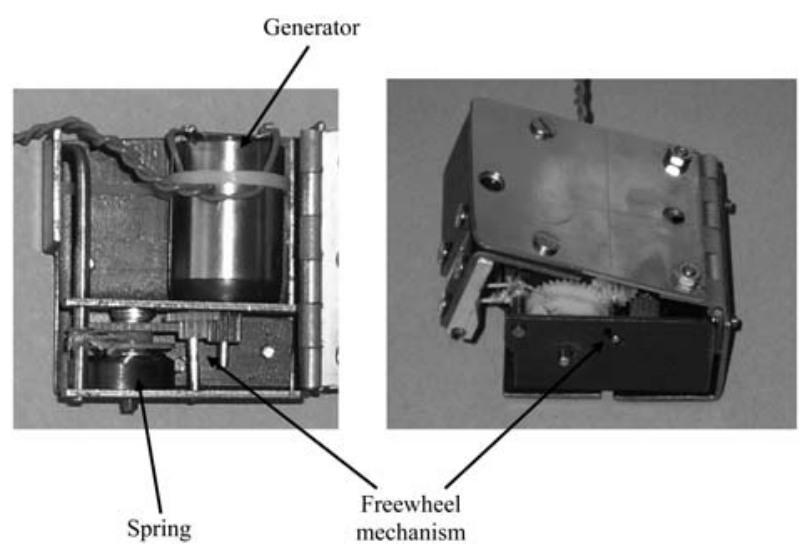

Fig. 6 Energy harvesting shoe insert

\section{Comparison of practical energy har- vesting devices}

A comparison of available energy harvesting devices in terms of their power output and power density is desirable but is difficult to achieve given the diverse operating modes. Beeby ${ }^{[51]}$ presented tabulated results for a range of vibration based devices grouped according to the conversion method. The same group ${ }^{[81]}$ presented a graphical comparison based on normalised power density (output power normalised for acceleration, $P_{\text {out }} / A^{2}$ ) but excluded the effect of frequency. Mitcheson et al. ${ }^{[8]}$ presented a comparison based on an estimate of efficiency which relied on assumptions about the input power supplied to the device. These comparisons were for vibration based devices only. We seek a comparison of the power which may be scavenged from available sources for a wider range of device types. Thus, we seek a comparison that combines the characteristics of the energy source and the efficiency of the conversion system. This necessitates a number of assumptions which may not be valid in all situations. These are summarised below and the numerical data for each device is given in Table 2. The data is presented graphically in Fig. 7. In some cases, it has been necessary to estimate values which are not explicitly given in the publications. These values are shown in italics in Table 2 .

For vibration based devices, performance is quoted for a given amplitude and frequency of vibration which may not be found in real environments. Thus, it is necessary to estimate the likely available vibration and normalise the performance to this. The available vibration is modelled as having an amplitude of $1 \mathrm{~ms}^{-2}$ at a frequency of $100 \mathrm{~Hz}$ with the amplitude being equal to $100 / f$ above and below 
this frequency. It is further assumed that the power generated is proportional to the square of the amplitude and so the normalised power becomes

$$
P_{n}=\frac{100 P}{A^{2} f} .
$$

This scaling does not attempt to take account of the fact that some devices may work more effectively than others at high or low amplitude vibrations.

The figures for shoe inserts have not been normalised since the data presented is for similar weight users walking at similar speeds. Solar cells, being essentially area devices, are generally specified in terms of $\mathrm{W} \cdot \mathrm{m}^{-2}$. However, here it is assumed that, in order to have sufficient mechanical rigidity, they must have a finite thickness or a suitable supporting framework and that as the device area increases, the thickness of the support must also increase. It is further assumed that the thickness is equal to $5 \%$ of the linear dimensions of the device so that volume, $V=0.05 \cdot$ Area $^{\frac{3}{2}}$. The available light for outdoor solar cell conversion is taken as the daily average value in winter at a temperate latitude, as discussed in Section 3.1, and the cell efficiency is assumed to be $15 \%$. The performance of PV cells is shown as a continuous line in Fig. 7 since the technology may be readily scaled to a desired size/power level. The thermoelectric device is based on a temperature difference of $5 \mathrm{~K}$.

It may be seen that similar types of devices give broadly similar power levels and are of similar volumes. The exception to this is vibration based devices using electromagnetic conversion but it may be noted that device 8 is a micromachined device while 9 and 10 are hand assembled "macro" machines. In terms of energy density, lines of equal power density are parallel to the lines shown for solar conversion, thus devices 1 and 10 demonstrate similar power densities. The highest power density of the devices considered is for EAP conversion (device 15) at approximately $1.25 \mu \mathrm{W} \cdot \mathrm{mm}^{-3}$ although this device was not expected to give long term operation. The typical energy density for the best performing devices is around $1 \mu \mathrm{W} \cdot \mathrm{mm}^{-3}$.

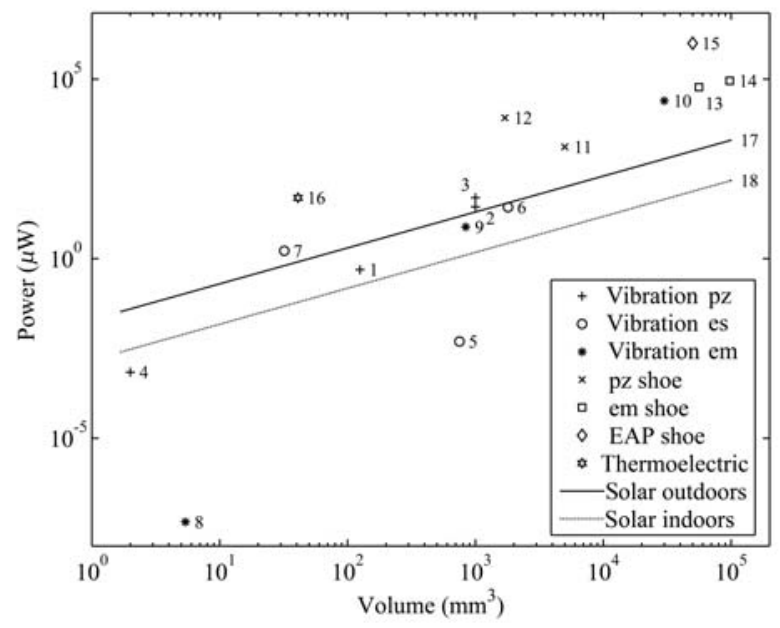

Fig. 7 Comparison of energy harvesting solutions

\section{Conclusions}

The nature of many sensor network systems means that energy harvesting is an attractive method of meeting their energy requirements. However, it is clear that a good understanding of the nature of the various energy sources and of the conversion mechanisms available is necessary if the most appropriate solution is to be found. Based on the published data considered, it can be seen that there is a large range of power levels and device volumes but that similar power densities are achieved for the best performing devices in each size range. Given the typical maximum power density available of around $1 \mu \mathrm{W} \cdot \mathrm{mm}^{-3}$ and the typical average power demands of a network node of around $3 \mathrm{~mW}$ for a

Table 2 Comparison on energy harvesting devices (pz: Piezo; es: electrostatic; em: electromagnetic)

\begin{tabular}{|c|c|c|c|c|c|c|c|}
\hline $\begin{array}{l}\text { Device } \\
\text { number }\end{array}$ & $\begin{array}{c}\text { Operating mode/ } \\
\text { material }\end{array}$ & Author ${ }^{[\text {reference }]}$ & $\begin{array}{l}\text { Output power } \\
(\mu \mathrm{W})\end{array}$ & $\begin{array}{c}\text { Frequency } \\
(\mathrm{Hz})\end{array}$ & $\begin{array}{c}\text { Amplitude } \\
\left(\mathrm{ms}^{-2}\right)\end{array}$ & $\begin{array}{c}\text { Normalised power } \\
\qquad(\mu \mathrm{W})\end{array}$ & $\begin{array}{l}\text { Volume } \\
\left(\mathrm{mm}^{3}\right)\end{array}$ \\
\hline 1 & Vibration - pz & Glynne-Jones $^{[55]}$ & 2.1 & 80.1 & 2.3 & 0.5 & 125 \\
\hline 2 & Vibration - pz & Roundy et al. ${ }^{[42,65]}$ & 210 & 120 & 2.5 & 28 & 1000 \\
\hline 3 & Vibration - pz & Roundy et al. ${ }^{[42]}$ & 375 & 120 & 2.5 & 50 & 1000 \\
\hline 4 & Vibration - pz & Marzencki et al. ${ }^{[90]}$ & 0.6 & 900 & 9.81 & 0.0007 & 2 \\
\hline 5 & Vibration - es & Mitcheson et al. ${ }^{[91]}$ & 3.7 & 30 & 50 & 0.005 & 750 \\
\hline 6 & Vibration - es & Despesse $1^{[72]}$ & 1052 & 50 & 8.8 & 27 & 1800 \\
\hline 7 & Vibration - es & Despesse $2^{[72]}$ & 70 & 50 & 9.2 & 1.7 & 32 \\
\hline 8 & Vibration - em & Shearwood and Yates ${ }^{[77]}$ & 0.3 & 4400 & 382 & $4.7 \times 10^{-8}$ & 5.4 \\
\hline 9 & Vibration - em & Glynne-Jones et al. ${ }^{[79]}$ & 180 & 322 & 2.7 & 7.7 & 840 \\
\hline 10 & Vibration - em & Perpetuum et al. ${ }^{[80]}$ & 4000 & 100 & 0.4 & 25000 & 30000 \\
\hline 11 & PVDF shoe stave & Schenk and Paradiso ${ }^{[92]}$ & & & & 1300 & 5000 \\
\hline 12 & PZT Dimorph & Schenk and Paradiso ${ }^{[92]}$ & & & & 8400 & 1700 \\
\hline 13 & em shoe insert & Schenk and Paradiso ${ }^{[92]}$ & & & & 60000 & 56000 \\
\hline 14 & em shoe insert & Gilbert (see Section 4.5.3) & & & & 90000 & 97500 \\
\hline 15 & EAP shoe insert & Pelrine et al. ${ }^{[84]}$ & & & & 1000000 & 50000 \\
\hline 16 & Thermoelectric & Applied digital solutions ${ }^{[47]}$ & & & & 50 & 41 \\
\hline 17 & PV cell (outdoor) & & & & & 20000 & 500000 \\
\hline 18 & PV cell (indoor) & & & & & 1500 & 500000 \\
\hline
\end{tabular}


node volume of around $10000 \mathrm{~mm}^{3}$ (excluding the power source) means that the volume of the energy harvesting device at around $3000 \mathrm{~mm}^{3}$ is a significant proportion of the overall node volume.

\section{References}

[1] I. Stojmenovic. Handbook of Sensor Networks: Algorithms and Architectures, John Wiley \& Sons Inc, Hoboken, New Jersey, USA, 2005.

[2] R. Jain, J. Wullert II. Challenges: Environmental Design for Pervasive Computing Systems. In Proceedings of the 8th Annual International Conference on Mobile Computing and Networking, ACM, New York, USA, pp. 263-270, 2002.

[3] K. Romer, F. Mattern. The Design Space of Wireless Sensor Networks. IEEE Wireless Communications Magazine, vol. 11, no. 6, pp. 54-61, 2004.

[4] K. Martinez, R. Ong, J. K. Hart, J. Stefanov. GLACSWEB: A Sensor Web for Glaciers. In Proceedings of European Workshop on Wireless Sensor Networks, Berlin, Germany, pp. 46-49, 2004.

[5] I. W. Marshall, C. Roadknight, I. Wokoma, L. Sacks. Self-organizing Sensor Networks. In Proceedings of UbiNet, London, UK, [Online], Available: http://wwwdse.doc.ic.ac.uk/Projects/UbiNet/ws2003/papers/marshall. pdf, 2003.

[6] D. Roemmich, S. Riser, R. Davis, Y. Desaubies. Autonomous Profiling Floats: Workhorse for Broadscale Ocean Observations. Marine Technology Society Journal, vol. 38, no. 1, pp. 31-39, 2004.

[7] R. Beckwith, D. Teibel, P. Bowen. Unwired Wine: Sensor Networks in Vineyards. In Proceedings of IEEE Sensors, IEEE Press, vol. 2, pp. 561-564, 2004.

[8] A. Mainwaring, D. Culler, J. Polastre, R. Szewczyk, J. Anderson. Wireless Sensor Networks for Habitat Monitoring. In Proceedings of the 1st ACM International Workshop on Wireless Sensor Networks and Applications, ACM, Atlanta, Georgia, USA, pp. 88-97, 2002.

[9] P. Juang, H. Oki, Y. Wang, M. Martonosi, L. S. Peh, D. Rubenstein. Energy-efficient Computing for Wildlife Tracking: Design Tradeoffs and Early Experiences with ZebraNet. In Proceedings of the 10th Architectural Support for Programming Languages and Operating Systems, ACM, San Jose, USA, vol. 36, no. 5, pp. 96-107, 2002.

[10] Z. Butler, P. Corke, R. Peterson, D. Rus. Virtual Fences for Controlling Cows. In Proceedings of IEEE International Conference on Robotics and Automation, IEEE Press, New Orleans, LA, USA, vol. 5, pp. 4429-4436, 2004.

[11] F. Michahelles, P. Matter, A. Schmidt, B. Schiele. Applying Wearable Sensors to Avalanche Rescue. Computers and Graphics, vol. 27, no. 6, pp. 839-847, 2003.

[12] UC Berkeley, MLB Company. The 29 Palms Fixed/Mobile Experiment: Tracking Vehicles with a UAV-delivered Sensor Network, [Online], Available: http://robotics.eecs.berkeley.edu/ pister/29Palms0103/, April 27, 2008.

[13] W. M. Merrill, F. Newberg, K. Sohrabi, W. Kaiser, G. Pottie. Collaborative Networking Requirements for Unattended Ground Sensor Systems. In Proceedings of IEEE Aerospace Conference, IEEE Press, Piscataway, USA, vol. 5, pp. 21532165, 2003.

[14] G. Simon, M. Maróti, Á. Lédezczi, G. Balogh, B. Kusy, A. Nádas, G. Pap, J. Sallai, K. Frampton. Sensor Network Based Countersniper System. In Proceedings of the 2nd International Conference on Embedded Networked Sensor Systems, ACM, Baltimore, Maryland, USA, pp. 1-12, 2004.
[15] S. H. Yang, P. Frederick. SafetyNET - A Wireless Sensor Network for Fire Protection and Emergency Responses. Measurement and Control, vol. 39, no. 7, pp. 218-219, 2006.

[16] C. Kappler, G. Riegel. A Real-world, Simple Wireless Sensor Network for Monitoring Electrical Energy Consumption. In Proceedings of European Workshop on Wireless Sensor Network, Lecture Notes in Computer Science, Springer-Verlag, vol. 2920, pp. 339-352 2004.

[17] N. Noury, T. Herve, V. Rialle, G. Virone, E. Mercier, G. Morey, A. Moro, T. Porcheron. Monitoring Behaviour in Home Using a Smart Fall Sensor. In Proceedings of the 1st Annual International Conference on Microtechnologies in Medicine and Biology, IEEE Press, Lyon, France, pp. 607-610, 2000.

[18] B. G. Celler, T. Hesketh, W. Earnshaw, E. Ilsar. An Instrumentation System for the Remote Monitoring of Changes in Functional Health Status of the Elderly. In Proceedings of the 16th Annual International Conference of the IEEE Engineering in Medicine and Biology Society, IEEE Press, New York, USA, vol. 2, pp. 908-909, 1994.

[19] G. Z. Yang. Body Sensor Networks, Springer-Verlag, Germany, 2006.

[20] N. F. Timmons, W. G. Scanlon. Analysis of the Performance of IEEE 802.15.4 for Medical Sensor Body Area Networking. In Proceedings of the 1st Annual IEEE Communications Society Conference on Sensor and Ad Hoc Communications and Networks, IEEE Press, pp. 16-24, 2004.

[21] L. Benini, E. Farella, C. Guiducci. Wireless Sensor Networks: Enabling Technology for Ambient Intelligence. Microelectronics Journal, vol. 37, no. 12, pp. 1639-1649, 2006.

[22] N. Correal, N. Patwari. Wireless Sensor Networks: Challenges and Opportunities. In Proceedings of MPRG/Virgina Tech Wireless Symposium on Wireless Personal Communication, Blacksburg, USA, pp. 1-9, 2001.

[23] P. Baronti, P. Pillai, V. W. C. Chook, S. Chessa, A. Gotta, Y. F. Hu. Wireless Sensor Networks: A Survey on the State of the Art and the 802.15.4 and ZigBee Standards. Computer Communications, vol. 30, no. 7, pp. 1655-1695, 2007.

[24] Z-wave alliance. The Z-wave Alliance Puts Total Control in your Hands, [Online], Available: http://www.zwavealliance.org/modules/start/, April 23, 2008.

[25] EnOcean, [Online], Available: http://www.enocean.com/ en/home/, April 23, 2008.

[26] S. C. Ergen. ZigBee/IEEE 802.15.4 Summary, [Online], Available: http://pages.cs.wisc.edu/ suman/courses/ 838/papers/zigbee.pdf, March 2008.

[27] Crossbow Products, [Online], Available: http://www. xbow.com/Products/productdetails.aspx?sid=164, May, 2008.

[28] Crossbow Products, [Online], Available: http://www. xbow.com/Products/productdetails.aspx?sid=253, May, 2008.

[29] Jennic Ltd. JN5139 Wireless Microcontroller (IEEE 802 15.4 and ZigBee), [Online], Available: http://www. jennic.com/products/index.php?productID $=0000000002$, May, 2008.

[30] J. L. Gonzalez, A. Rubio, F. Moll. Human Powered Piezoelectric Batteries to Supply Power to Wearable Electronic Devices. International Journal of Society of Materials Engineering for Resources, vol. 10, no. 1, pp. 34-40, 2001.

[31] T. E. Starner. Powerful Change Part 1: Batteries and Possible Alternatives for the Mobile Market. IEEE Pervasive Computing, vol. 2, no. 4, pp. 86-88, 2003.

[32] S. Roundy, D. Steingart, L. Frechette, P. Wright, J. Rabaey. Power Sources for Wireless Sensor Networks. Lecture Notes in Computer Science, Springer-Verlag, vol. 2920, pp. 1-17, 2004 
[33] L. Mateu, F. Moll. Review of Energy Harvesting Techniques and Applications for Microelectronics. In Proceedings of SPIE - The International Society for Optical Engineering, VLSI Circuits and Systems II, SPIE Press, vol. 5837, pp. 359-373, 2005.

[34] T. von Büren. Body-worn Inertial Electromagnetic Microgenerators, Ph. D. dissertation ETH 16466, Swiss Federal Institute of Technology, Zurich, Germany, 2006.

[35] A. H. Sellers, P. J. Robinson. Contemporary Climatology, Longman Scientific \& Technical, Essex, UK, 1986.

[36] J. L. Monteith, M. H. Unsworth. Principles of Environmental Physics, Edward Arnold, London, UK, 1990.

[37] S. J. Roundy. Energy Scavenging for Wireless Sensor Nodes with a Focus on Vibration to Electricity Conversion, Ph. D. dissertation, University of California, Berkeley, USA, 2003.

[38] K. Finkenzeller. RFID Handbook: Fundamentals and Applications in Contactless Smart Cards and Identification, John Wiley \& Sons, 2003.

[39] T. Starner. Human-powered Wearable Computing. IBM Systems Journal, vol. 35, no. 3, pp. 618-629, 1996.

[40] Highway Energy Systems Ltd., [Online], Available: http://www.hughesresearch.co.uk/, March 6, 2008.

[41] M. Trew, T. Everett. Human Movement: An Introductory Text, Churchill Livingstone, 2001.

[42] S. J. Roundy, P. K. Wright, J. Rabaey. A Study of Low Level Vibrations as a Power Source for Wireless Sensor Nodes. Computer Communications, vol. 26, no. 11, pp. 1131-1144, 2003

[43] F. M. Discenzo, D. Chung, K. A. Loparo. Power Scavenging Enables Maintenance-free Wireless Sensor Nodes. In Proceedings of the 6th International Conference on Complex Systems, Boston, USA, 2006, [Online], Available: http://necsi.org/events/iccs6/papers/7df7ed07961c3fb28cf d2f851d82.pdf

[44] M. A. Gree. Third Generation Photovoltaics: Advanced Solar Energy Conversion, Springer, Germany, 2005.

[45] T. Starner, J. A. Paradiso. Human-generated Power for Mobile Electronics. Low-Power Electronics Design, C. Piguet (ed.), CRC Press, Chapter 45, pp. 1-35, 2004.

[46] M. Stordeur, I. Stark. Low Power Thermoelectric Generator - Self-sufficient Energy Supply for Micro Systems. In Proceedings of International Conference on Thermoelectrics XVI, IEEE Press, pp. 575-577, 1997.

[47] Thermo Life Energy Corp., [Online], Available: http://www.poweredbythermolife.com/, April 17, 2008.

[48] Y. Yumita, H. Kumagai. Hydraulic Power Generating Device, United States Patent 7005758 B2, February 2006.

[49] A. S. Holmes, G. Hong, K. R. Pullen, K. R. Buffard. Axialflow Microturbine with Electromagnetic Generator: Design, CFD Simulation, and Prototype Demonstration. In Proceedings of the 17th IEEE International Conference on $\mathrm{Mi}$ cro Electro Mechanical Systems, IEEE Press, pp. 568-571, 2004.

[50] C. Federspiel, J. Chen. Air-powered Sensor, [Online], Available: http://repositories.cdlib.org/cedr/cbe/cit/ Federspiel2003_AirPoweredSensor, May 2008.

[51] S. P. Beeby, M. J. Tudor, N. M. White. Review Paper: Energy Harvesting Vibration Sources for Microsystems Applications. Measurement Science and Technology, vol. 17, no. 12, pp. 175-195, 2006.

[52] C. D. Richards, M. J. Anderson, D. F. Bahr, R. F. Richards. Efficiency of Energy Conversion for Devices Containing a Piezoelectric Component. Journal of Micromechanics and Microengineering, vol. 14, no. 5, pp. 717-721, 2004.

[53] S. R. Anton, H. A. Sodano. A Review of Power Harvesting Using Piezoelectric Materials (2003-2006). Smart Materials and Structures, vol, 16, no. 3, pp. 1-21, 2007.
[54] H. S. Yoon, G. Washington, A. Danak. Modeling and Design of Efficient Initially-curved Piezoceramic Unimorphs for Energy Harvesting Applications. Journal of Intelligent Material Systems and Structures, vol. 16, no. 10, pp. 877888, 2005.

[55] P. Glynne-Jones, S. P. Beeby, N. M. White. Towards a Piezoelectric Vibration-powered Microgenerator. IEE Proceedings of Science, Measurement and Technology , vol. 148, no. 2, pp. 68-72, 2001.

[56] S. Roundy, E. S. Leland, J. Baker, E. Carleton, E. Reilly, E. Lai, B. Otis, J. M. Rabaey, P. K. Wright, V. Sundararajan. Improving Power Output for Vibration-based Energy Scavengers. IEEE Pervasive Computing, vol. 4 , no. 1, pp. $28-36,2005$.

[57] J. Baker, S. Roundy, P. K. Wright. Improvements in Vibration Energy Scavenging for Wireless Sensor Networks. In Proceedings of the 3rd International Energy Conversion Engineering Conference, San Francisco, USA, 2005.

[58] S. J. Roundy, P. K. Wright. A Piezoelectric Vibration Based Generator for Wireless Electronics. Smart Materials and Structures, vol. 13, no. 5, pp. 1131-1142, 2004.

[59] H. A. Sodano, E. A. Magluila, G. Park, D. J. Inman. Electric Power Generation Using Piezoelectric Materials. In Proceedings of the 13th International Conference on Adaptive Structures and Technologies, CRC Press, pp. 153-161, 2002.

[60] H. A. Sodano, D. J. Inman, G. Park. A Review of Power Harvesting from Vibration Using Piezoelectric Materials. The Shock and Vibration Digest, vol. 36, no. 3, pp. 197205, 2004.

[61] T. H. Ng, W. H. Liao. Sensitivity Analysis and Energy Harvesting for a Self-powered Piezoelectric Sensor. Journal of Intelligent Material Systems and Structures, vol. 16, no. 10, pp. 785-797, 2005.

[62] K. Mossi, C. Green, Z. Ounaies, E. Hughes. Harvesting Energy Using a Thin Unimorph Prestressed Bender: Geometrical Effects. Journal of Intelligent Material Systems and Structures, vol. 16, no. 3, pp. 249-261, 2005.

[63] A. D. Danak, H. S. Yoon, G. N. Washington. Optimization of Electrical Output in Response to Mechanical Input Piezoceramic Laminated Shells. In Proceedings of ASME International Mechanical Engineering Congress, ASME Press, Washington DC, USA, vol. 68, pp. 309-316, 2003.

[64] P. J. Cornwell, J. Goethal, J. Kowko, M. Damianakis. Enhancing Power Harvesting Using a Tuned Auxiliary Structure. Journal of Intelligent Material Systems and Structures, vol. 16, no. 10, pp. 825-834, 2005.

[65] S. J. Roundy, Y. Zhang. Toward Self-tuning Adaptive Vibration-based Microgenerators. In Proceedings of SPIE, Smart Structures, Devices, and Systems II, S. F. Al-Sarawi (ed.), SPIE Press, Sydney, Australia, vol. 5649, pp. 373384, 2005.

[66] W. J. Wu, Y. Y. Chen, B. S. Lee, J. J. He, Y. T. Peng. Tunable Resonant Frequency Power Harvesting Devices. In Proceedings of SPIE, Smart Structures and Materials 2006: Damping and Isolation, W. W. Clark, M. Ahmadian, A. Lumsdaine (eds.), SPIE Press, San Diego, CA, USA, vol. 6169, pp. 55-62, 2006.

[67] S. M. Shahruz. Design of Mechanical Band-pass Filters for Energy Scavenging. Journal of Sound and Vibration, vol. 292, no. 3-5, pp. 987-998, 2006.

[68] S. M. Shahruz. Limits of Performance of Mechanical Bandpass Filters Used in Energy Scavenging. Journal of Sound and Vibration, vol. 293, no. 1-2, pp. 449-461, 2006.

[69] J. Rastegar, C. Pereira, H. L. Nguyen. Piezoelectric-based Power Sources for Harvesting Energy from Platforms with Low-frequency Vibration. In Proceedings of SPIE, Smart Structures and Materials 2006: Industrial and Commercial Applications, E. V. White (ed.), SPIE Press, San Diego, CA, USA, vol. 6171, pp. 1-7, 2006. 
[70] S. Meninger, J. O. Mur-Miranda, R. Amirtharajah, A. P. Chandrakasan, J. H. Lang. Vibration to Electric Energy Conversion. IEEE Transactions on Very Large Scale Integration Systems, vol. 9, no. 1, pp. 64-76, 2001.

[71] W. Ma, M. Wong, L. Ruber. Dynamic Simulation of an Implemented Electrostatic Power Micro-generator. In Proceedings of Design, Test, Integration and Packaging of MEMS/MOEMS, Montreux, Switzerland, pp. 380-385, 2005.

[72] G. Despesse, T. Jager, J. J. Chaillout, J. M. Léger, A. Vassilev, S. Basrour, B. Charlot. Fabrication and Characterization of High Damping Electrostatic Micro Devices for Vibration Energy Scavenging. In Proceedings of Design, Test, Integration and Packaging of MEMS/MOEMS, Montreux, Switzerland, pp. 386-390, 2005.

[73] R. Tashiro, N. Kabei, K. Katayama, E. Tsuboi, K. Tsuchiya. Development of an Electrostatic Generator for a Cardiac Pacemaker that Harnesses the Ventricular Wall Motion. Journal of Artificial Organs, vol. 5, no. 4, pp. 239245, 2002.

[74] M. El-hami, P. Glynne-Jones, N. M. White, M. Hill, S. P. Beeby, E. James, A. D. Brown, J. N. Ross. Design and Fabrication of a New Vibration Based Electromechanical Generator. Sensors and Actuators: A Physical, vol. 92, no. 1-3, pp. 335-342, 2001.

[75] N. G. Stephen. On Energy Harvesting from Ambient Vibration. Journal of Sound and Vibration, vol. 293, no. 1-2, pp. 409-425, 2006

[76] C. B. Williams, C. Shearwood, M. A. Harradine, P. H. Mellor, T. S. Birch, R. B. Yates. Development of an Electromagnetic Micro-generator. IEE Proceedings of Circuits, Devices and Systems, vol. 148, no. 6, pp. 337-342, 2001.

[77] C. Shearwood, R. B. Yates. Development of an Electromagnetic Microgenerator. Electronics Letters, vol. 33, no. 22, pp. 1883-1884, 1997.

[78] H. Kulah, K. Najafi. An Electromagnetic Micro Power Generator for Low-frequency Environmental Vibrations. In Proceedings of the 17th IEEE Conference on Micro Electro Mechanical Systems, IEEE Press, Maastricht, Netherlands, pp. $237-240,2004$

[79] P. Glynne-Jones, M. J. Tudor, S. P. Beeby, N. M. White. An Electromagnetic, Vibration-powered Generator for Intelligent Sensor Systems. Sensors and Actuators: A Physical, vol. 110, no. 1-3, pp. 344-349, 2004.

[80] Perpetuum Ltd, [Online], Available: http:// www.perpetuum.co.uk/, March 6, 2008

[81] S. P. Beeby, R. N. Torah, M. J. Tudor, P. Glynne-Jones, T. O'Donnell, C. R. Saha, S. Roy. A Micro Electromagnetic Generator for Vibration Energy Harvesting. Journal of Micromechanics and Microengineering, vol. 17, no. 7, pp. $1257-1265,2007$.

[82] J. F. Antaki, G. E. Bertocci, E. C. Green, A. Nadeem T. Rintoul, R. L. Kormos, B. P. Griffith. A Gait-powered Autologous Battery Charging System for Artificial Organs. Journal of American Society for Artificial Internal Organs, vol. 41 , no. 3 , pp. 588-595, 1995 .

[83] N. W. Hagood IV, D. C. Roberts, L. Saggere, M. A. Schmidt, M. Spearing, K. S. Breuer, R. Mlcak, J. A. Carrerero, et al. Development of Micro-hydraulic Transducer Technology. In Proceedings of the 10th International Conference on Adaptive Structures and Technologies, Paris, France, pp. 71-81, 1999.
[84] Heelstrike generator report, SRI International Medtronic Forum, [Online], Available: http://handle.dtic.mil/100.2/ ADA414020, April 2, 2008

[85] R. Pelrine, R. D. Kornbluh, J. Eckerle, P. Jeuck, S. Oh, Q. Pei, S. Stanford. Dielectric Elastomers: Generator Mode Fundamentals and Applications. In Proceedings of SPIE, Smart Structures and Materials 2001: Electroactive Polymer Actuators and Devices, SPIE Press, Yoseph Bar-Cohen (ed.), vol. 4329, pp. 148-156, 2001.

[86] J. Hayashida. Unobtrusive Integration of Magnetic Generator Systems into Common Footwear, B.Sc. dissertation, Department of Electrical Engineering and MIT Media Laboratory, Massachusetts Institute of Technology, Cambridge, Massachusetts, USA, 2000.

[87] J. Kymissis, C. Kendall, J. Paradiso, N. Gershenfeld. Parasitic Power Harvesting in Shoes. In Proceedings of IEEE International Conference on Wearable Computing, IEEE Press, pp. 132-139, 1998.

[88] J. M. Gilbert, R. S. Oldaker, J. E. Grindley, P. M. Taylor. Control of a Novel Switched Mode Variable Ratio Drive. In Proceedings of UKACC International Conference on Control, vol. 1, pp. 412-417, 1996.

[89] P. D. Mitcheson, E. K. Reilly, P. K. Wright, E. M. Yeatman. Transduction Mechanisms and Power Density for MEMS Inertial Energy Scavengers. In Proceedings of Power MEMS, Berkeley, USA, pp. 275-278, 2006.

[90] M. Marzencki, S. Basrour, B. Charlot, A. Grasso, M. Colin, L. Valbin. Design and Fabrication of Piezoelectric Micro Power Generators for Autonomous Microsystems. In Proceedings of Design, Test, Integration and Packaging of MEMS/MOEMS, Montreux, Switzerland, pp. 299-302, 2005

[91] P. D. Mitcheson, B. H. Stark, P. Miao, E. M. Yeatman, A. S. Holmes, T. C. Green. Analysis and Optimisation of MEMS Electrostatic On-chip Power Supply for Self-powering of Slow-moving Sensors. In Proceedings of the 17th European Conference on Solid-state Transducers (Eurosensors XVII), Portugal, pp. 48-51, 2003.

[92] N. S. Shenck, J. A. Paradiso. Energy Scavenging with Shoemounted Piezoelectrics. IEEE Micro, vol. 21, no. 3, pp. 3042,2001

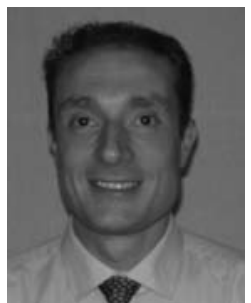

James M. Gilbert graduated from the University of Hull, UK, with a bachelor degree in electronic engineering in 1986 and with Ph. D. in robot control in 1989. He has since been a lecturer in the Department of Engineering at the same university.

His research interest includes energy harvesting devices, particularly for sensor network applications.

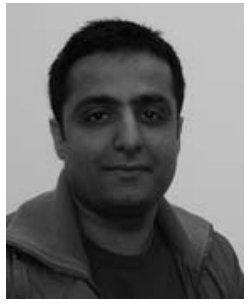

Farooq Balouchi obtained M. Eng. degree from Department of Engineering the University of Hull, UK, in 2006. He is currently a $\mathrm{Ph}$. D. candidate in energy harvesting for wireless and actuator networks.

His research interest includes developing innovative mechanisms for harvesting energy from human movement, specifically mechanisms which are embedded under sprung floors and stairwells. 